\title{
Nitric Oxide Generator Based on Pulsed Arc Discharge
}

\author{
S. Sakai, M. Matsuda, D. Wang, T. Naminira*, H. Akiyama, K. Okamoto and \\ K. TODA \\ Bioelectrics Research Center, Kumamoto University \\ 2-39-1 Kurokami, Kumamoto 860-8555, Japan
}

\begin{abstract}
Nitric oxide (NO) is increasingly being used in medical applications. Currently, a gas cylinder of $\mathrm{N}_{2}$ mixed with a high concentration of NO is used in the NO inhalation system. However, this arrangement is potentially risky due to the possibility of accidental leak of NO from the cylinder. The presence of NO in air leads to the formation of nitric dioxide $\left(\mathrm{NO}_{2}\right)$, which is toxic to the lungs. Therefore, an on-site generation of NO would be very desirable for patients with acute respiratory distress syndrome and other related illnesses. Previously, our group reported the production of NO using a pulsed arc discharge. In this work, the prototype of the on-site NO generator was developed and the performances of the NO generator were demonstrated for medical applications.
\end{abstract}

PACS numbers: $52.80 . \mathrm{Mg}$

\section{Introduction}

It is well known that nitrogen oxide $\left(\mathrm{NO}_{x}\right)$ is produced by nitrogen fixation of bacteria, combustion of fossil fuel, natural lightning stroke and so on. Bacteria produces nitric dioxide $\left(\mathrm{NO}_{2}\right)$, and the others generate nitric oxide (NO). In the atmosphere, $\mathrm{NO}$ is immediately oxidized to $\mathrm{NO}_{2}$ by oxygen $\left(\mathrm{O}_{2}\right)$ or ozone $\left(\mathrm{O}_{3}\right)$. Because $\mathrm{NO}_{x}$ is toxic for human being, many researchers have studied about its removal [1-3]. On the other hand, NO is well known as one of the most important molecules within the living human body in the medical field. It is well known that $\mathrm{NO}$ is related to the memory, the attack of pathogens and the vessel relaxation. Especially, the blood vessel relaxation effect found by Ignarro et al. in 1987 [4] has had a lot of attention from the medical doctors. In the literature [4], NO was introduced as endothelium-derived relaxing factor (EDRF) within the living body. From the discovery, many medical doctors and researchers started the investigation of applications of $\mathrm{NO}$ into a medical treatment. As a result, $\mathrm{NO}$ inhalation therapy has been developed and used for some lung diseases such as acute respiratory distress syndrome (ARDS) or persistent pulmonary hypertension of the newborn (PPHN), in these days. Currently a system of NO inhalation has a gas cylinder of nitrogen $\left(\mathrm{N}_{2}\right)$ mixed with a high concentration of NO. NO from the gas cylinder is introduced to patients after attenuation by air or $\mathrm{O}_{2}$. However, this system is potentially risky due to the possibility of accidental leak of NO from the cylinder. In addition, gas cylinder is too heavy to carry and is very expensive to

* corresponding author; e-mail: namihira@cs.kumamoto-u.ac.jp use for long time. Therefore, an on-site production of NO with low cost would be highly desirable for patients and medical doctors. We have reported the production of NO based on a pulsed arc discharge [5-7]. In the present work, NO generator based on a pulsed arc discharge was developed and it was evaluated as the medical device.

\section{NO generation by pulsed arc discharge}

Air mainly consists of $\mathrm{N}_{2}$ and $\mathrm{O}_{2}$ and these molecules could be an origin of NO. NO is produced and decomposed in a mixture of $\mathrm{N}_{2}$ and $\mathrm{O}_{2}$ via following equations [8]:

$$
\begin{aligned}
& \mathrm{O}_{2}+\mathrm{e} \rightarrow \mathrm{O}+\mathrm{O}+\mathrm{e}, \\
& \mathrm{O}_{2}+\mathrm{e} \rightarrow \mathrm{O}+\mathrm{O}^{*}\left({ }^{1} D\right)+\mathrm{e}, \\
& \mathrm{N}_{2}^{*}\left(A^{3} \sum_{u}^{+}\right)+\mathrm{O} \rightarrow \mathrm{NO}+\mathrm{N}^{*}\left({ }^{2} D\right), \\
& \mathrm{N}^{*}\left({ }^{2} D\right)+\mathrm{O}_{2} \rightarrow \mathrm{NO}+\mathrm{O}, \\
& \mathrm{O}+\mathrm{NO}_{2} \rightarrow \mathrm{NO}+\mathrm{O}_{2}, \\
& \mathrm{~N}_{2}^{*}\left(A^{3} \sum_{u}^{-}\right)+\mathrm{NO} \rightarrow \mathrm{N}_{2}+\mathrm{N}+\mathrm{O}, \\
& \mathrm{N}+\mathrm{NO} \rightarrow \mathrm{N}_{2}+\mathrm{O}, \\
& \mathrm{O}^{*}\left({ }^{1} D\right)+\mathrm{NO} \rightarrow \mathrm{N}+\mathrm{O}_{2}, \\
& \mathrm{O}_{3}+\mathrm{NO} \rightarrow \mathrm{NO}_{2}+\mathrm{O}_{2} .
\end{aligned}
$$

Under high temperature plasma, the reaction starts with a decomposition of $\mathrm{O}_{2}$ to $\mathrm{O}$ atoms and $\mathrm{NO}$ is mainly generated through a collision of $\mathrm{N}_{2}^{*}\left(A^{3} \sum_{u}^{+}\right)$and $\mathrm{O}$ atoms, Eq. (3). $\mathrm{NO}_{2}$ is also produced by a reaction of $\mathrm{NO}$ and $\mathrm{O}_{3}$, Eq. (9), or $\mathrm{O}_{2}$. 


\section{Performance of developed NO generator}

The developed NO generator consists of the point to plane type electrode as a discharge chamber, the capacitor $(190 \mathrm{pF})$ discharge circuit with the control board, an air pump and a particle filter. The air pump introduced the ambient air at $300 \mathrm{~mL}$ to the discharge chamber and the particle filter trapped the metal particle from the arc discharge. In this time, the distance of the point to plane electrodes and the charging voltage of the energy stored capacitor are fixed at $5 \mathrm{~mm}$ and $10 \mathrm{kV}$, respectively. (Fig. 1 shows waveforms of the applied voltage to and the discharge current in the electrode.)

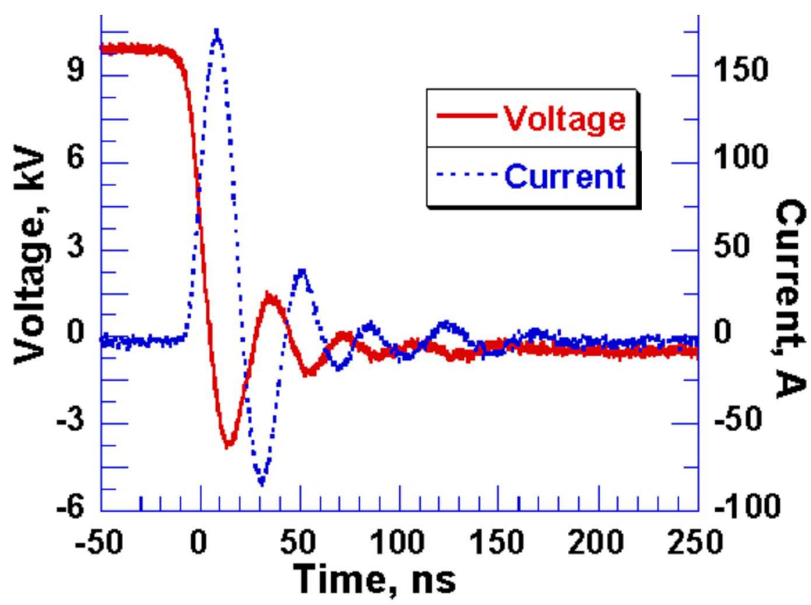

Fig. 1. Typical waveforms of applied voltage to and discharge current through discharge chamber.

As one of the performances of the developed NO generator, the concentration of NO increased linearly with the pulse repetition rate. This is because the input energy to the discharge plasma increased with the repetition rate. The demand of NO concentration in medical applications is over $1000 \mathrm{ppm}$ at flow rate of $300 \mathrm{~mL}$. The pulsed repetition rate of $280 \mathrm{pps}$ is suitable for the $\mathrm{NO}$ generator. Of course, the NO concentration is controllable by the adjustment of the pulse repetition rate.

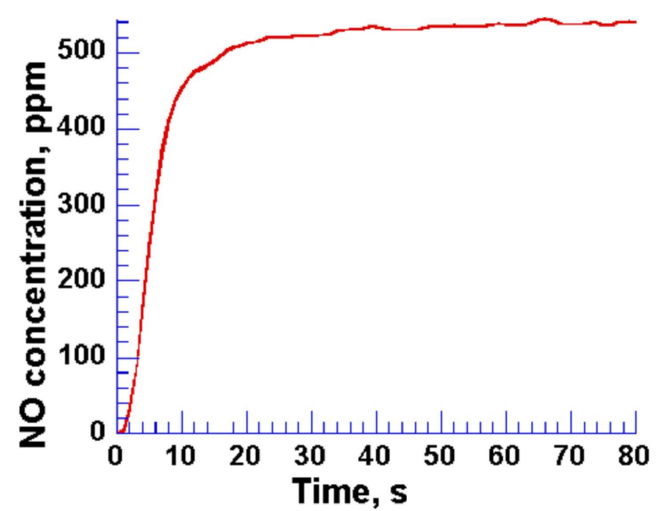

Fig. 2. Approach time to required NO concentration.

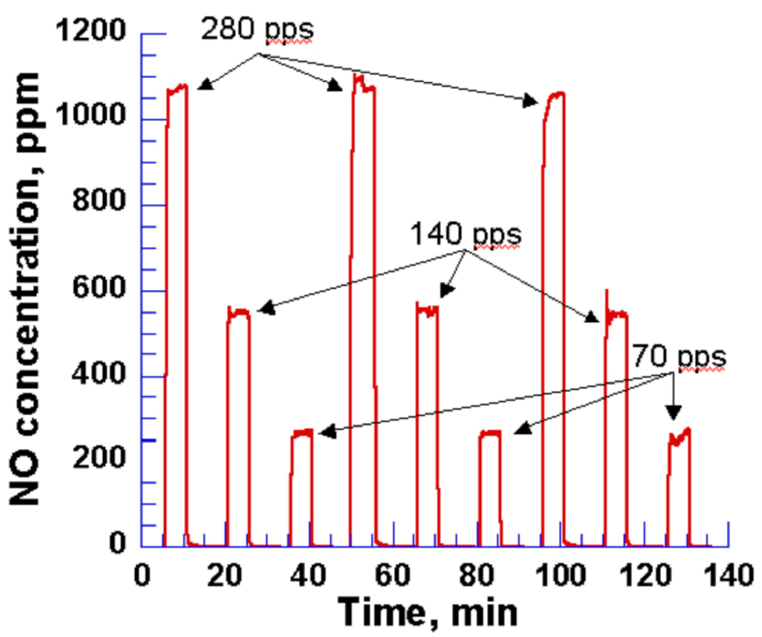

Fig. 3. NO concentration reproducibility of developed generator.

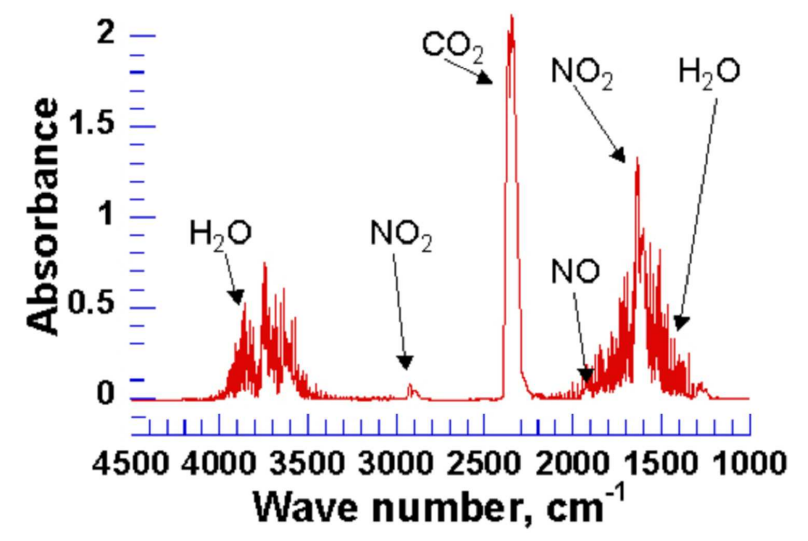

Fig. 4. FT-IR spectrum of output gas from developed generator.

The NO inhalation therapy is sometimes needed for emergency case. The warm-up time of a medical device should be short. Figure 2 shows the warm-up time of the developed NO generator. From Fig. 2, the time to achieve the required concentration of NO is less than $30 \mathrm{~s}$. It should be sufficient for medical applications.

The reproducibility of and the lifetime of medical device are also important factors. Figure 3 indicates the result of the confirmation test of the generator's reproducibility. In the test, three concentrations were required for three times. From the results, the reproducibility of NO concentration was less than $2.0 \%$ for $1061 \mathrm{ppm}$. As the result of the lifetime test, the $75 \mathrm{~h}$ operation with no maintenance was demonstrated. After 75 hours, the discharge became gradually unstable and $\mathrm{NO}$ concentration decreased with operation time. However, the discharge and the NO concentration could be stable by re-setting of the discharge parameters. This means that the NO generator needs the feed-back control from $\mathrm{NO}$ concentration to the discharge parameters for long time operation. 
The Fourier transform infrared (FT-IR) spectrum of the output gas from $\mathrm{NO}$ generator is shown in Fig. 4. It can be observed from Fig. 4 that the output gas included only $\mathrm{NO}, \mathrm{NO}_{2}, \mathrm{CO}_{2}$ and $\mathrm{H}_{2} \mathrm{O}$. $\mathrm{NO}$ and $\mathrm{NO}_{2}$ are from the reactions in the discharge plasma discussed in Sect. 2. Meanwhile, $\mathrm{CO}_{2}$ and $\mathrm{H}_{2} \mathrm{O}$ might come from the ambient air. It is also well known that ozone is produced by the discharge. However, the NO generator has no ozone. This might be because all ozone generated by the discharge reacted with $\mathrm{NO}$ immediately after the generation. As a result, it must be considered that the developed NO generator needs the device or the function for $\mathrm{NO}_{2}$ removal from the output gas.

\section{Conclusions}

In this paper, the detailed performances of a prototype device of NO generator based on pulsed arc discharge has been demonstrated. The followings are summary of the performances of the developed NO generator:

- The discharge treated gas includes $\mathrm{NO}, \mathrm{NO}_{2}, \mathrm{CO}_{2}$ and $\mathrm{H}_{2} \mathrm{O}$.

- The concentration of NO is controlled by the pulse repetition rate.

- The warm-up time of the generator is less than $30 \mathrm{~s}$.

- The reproducibility of NO concentration is less than $2.0 \%$ at $1061 \mathrm{ppm}$.

- The lifetime of the generator is $75 \mathrm{~h}$ under no maintenance condition.

- The generator needs the removal unit of $\mathrm{NO}_{2}$.

\section{Acknowledgments}

This study was supported by Industrial Technology Research Grant Program in '05 from New Energy and Industrial Technology Development Organization (NEDO) of Japan.

\section{References}

[1] T. Namihira, S. Tsukamoto, D. Wang, S. Katsuki, R. Hackam, H. Akiyama, Y. Uchida, M. Koike, IEEE Trans. Plasma Sci. 28, 434 (2000).

[2] S. Masuda, H. Nakao, IEEE Trans. Industry Appl. 26, 374 (1990).

[3] A. Mizuno, K. Shimmizu, A. Chakrabarti, L. Dascalescu, S. Furuta, IEEE Trans. Industry Appl. 31, 957 (1995).

[4] R.M. Palmer, A.G. Ferrige, S. Moncada, Nature 327, 524 (1987).

[5] T. Namihira, S. Tsukamoto, D. Wang, S. Katsuki, R. Hackam, K. Okamoto, H. Akiyama, IEEE Trans. Plasma Sci. 28, 109 (2000).

[6] T. Namihira, S. Katsuki, R. Hackam, H. Akiyama, K. Okamoto, IEEE Trans. Plasma Sci. 30, 1993 (2002).

[7] T. Namihira, S. Sakai, M. Matsuda, D. Wang, T. Kiyan, H. Akiyama, K. Okamoto, K. Toda, Plasma Sci. Technol. 9, 747 (2007).

[8] Y. Tanaka, T. Michishita, Y. Uesugi, Plasma Sources Sci. Technol. 14, 134 (2005). 